\title{
Statistical modelling of the influence of the stress ratio on the fatigue strength estimation. Application on specimens coming from riveted structures.
}

\author{
Paul Dario Toasa Caiza ${ }^{1}$, Stephane Sire $^{2}$, Bernard Espion ${ }^{3}$, and Muriel Ragueneau ${ }^{4}$ \\ ${ }^{1}$ Karlsruher Institut fur Technologie \\ ${ }^{2}$ Affiliation not available \\ ${ }^{3}$ Universite Libre de Bruxelles \\ ${ }^{4}$ SNCF Réseau
}

March 8, 2021

\begin{abstract}
As testimony of the engineering development during the industrial revolution, old riveted bridges are maintained by several policies worldwide and in some cases because of their historical importance protected. A main concern of these policies is preserving their structural integrity, which depends on a fatigue assessment of their components and assemblies. In these structures, the stress ratio considerably affects the fatigue strength, but the actual standards do not consider this fact. Some deterministic models have been proposed in order to overcome this issue. However, they are based on restrictive and empirical assumptions. Moreover, no statistical considerations are made, although fatigue strength is a random variable. In this paper, the suggested models are studied and then enhanced by statistical considerations. Finally, a statistical fatigue strength model as function of the stress ratio is proposed and applied on riveted specimens from old German Bridges and newly manufactured specimens of steel S235.
\end{abstract}

\section{Hosted file}

Toasa_Sire_V6.pdf available at https://authorea.com/users/400121/articles/512487-statisticalmodelling-of-the-influence-of-the-stress-ratio-on-the-fatigue-strength-estimationapplication-on-specimens-coming-from-riveted-structures 